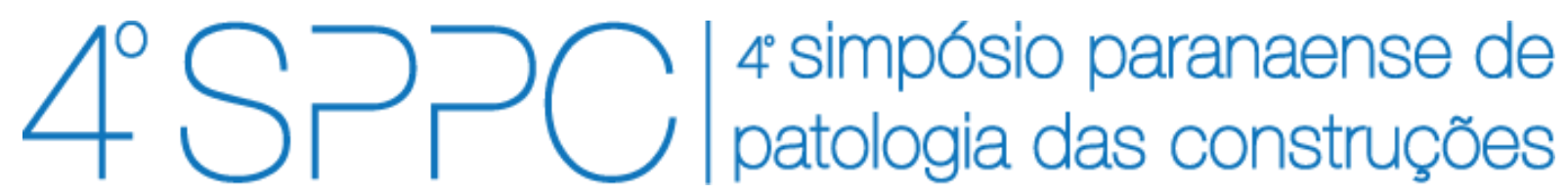

ISSN 2526-7248 artigo n. 4SPPC146, pp. 411-419, 2019

\title{
Investigação do microrganismo Lysinibacillus sphaericus como agente de autocicatrização em materiais de base cimentícia
}

\author{
Oliveira, Isaac Aguiar ${ }^{1}$; Anjos, Juliane Cristine Santos²; Medeiros, Marcelo Henrique \\ Farias $^{3}$ \\ ${ }^{1}$ Mestre, Universidade Federal do Paraná, zacaguiar@gmail.com \\ ${ }^{2}$ Aluna de Iniciação Científica, Universidade Federal do Paraná, \\ jucristine123@gmail.com \\ ${ }^{3}$ Doutor, Universidade Federal do Paraná, medeiros.ufpr@gmail.com
}

Resumo: A autocicatrização em materiais à base de concreto ocorrem com o intuito de tamponar microfissuras que possa ocasionar a entrada de agentes deletérios para o material. Nesse contexto, o objetivo deste trabalho é estudar o microrganismo Lysinibacillus sphaericus e submete-lo a testes que comprovem a sua aplicabilidade em estruturas de concreto para atuarem como agentes de cicatrização. Para isso, o mesmo foi exposto ao crescimento em meio de cultura com diferentes pH's alcalinos. Depois, foi verificada a concentração dos microrganismos no meio de cultura pelo método da contagem por placas. Após essa etapa o microrganismo foi submetido ao crescimento por 14 dias em um meio de cultura líquido rico em cálcio para verificar a capacidade do mesmo em precipitar minerais de carbonato de cálcio. As investigações dos minerais precipitados foram feitas por DRX e MEV. A bactéria Lysinibacillus sphaericus precipitou o mineral carbonato de cálcio e apresentou crescimento em meio de cultura com $\mathrm{pH}$ alcalino, o que mostra que o microrganismo é apto a ser aplicado como agente de cicatrização em materiais de base cimentícia.

Palavras-chave: Microrganismo, autocicatrização, Lysinibacillus sphaericus, carbonato de Cálcio.

Abstract: Self-healing in concrete-based materials occurs with the purpose to fill
microcracks that may lead to the entry of deleterious agents into the material. In this
context, the aim of this work is to study the microorganism Lysinibacillus sphaericus
and to submit it to tests that prove its applicability in concrete structures to act as
healing agents. For this, it was exposed to growth in culture medium with different
alkaline pH's. Then, the concentration of the microorganisms in the culture medium
was verified by the plate counting method. Then the microorganism was subjected to
growth for 14 days in a calcium rich liquid culture medium to verify the ability of the
microorganism to precipitate calcium carbonate minerals. The investigations of the
minerals were done by XRD and SEM. The bacterium Lysinibacillus sphaericus
precipitated the calcium carbonate mineral and presented growth in culture medium
with alkaline pH, which shows that the microorganism can be applied as a healing
agent in cementitious materials.

Keywords: Microorganism, self-healing, Lysinibacillus sphaericus, calcium carbonate. 
OLIVEIRA, I. A.; ANJOS, J. C. S.; MEDEIROS, M. H. F. INVESTIGAÇÃO DO MICRORGANISMO LYSINIBACILLUS SPHAERICUS COMO AGENTE DE AUTOCICATRIZAÇÃO EM MATERIAIS DE BASE CIMENTÍ́CIA. $4^{\circ}$ Simpósio Paranaense de Patologia das Construções (40 SPPC), artigo 4SPPC146, pp. 411 - 419, 2019. DOI: 10.4322/2526-7248.063

\section{Introdução}

Os materiais autocicatrizantes podem ser definidos como os que possuem a habilidade de se auto reparar sem intervenção externa [1 - 2]. De acordo com Zwaag [3], um objetivo recorrente do desenvolvimento dos materiais autocicatrizantes foi 0 de imitar os materiais da natureza para que sejam evitados danos decorrentes do uso do material.

Em todas as estruturas de concreto as microfissuras estão sujeitas a ocorrerem por atuações de tensões internas à peça, que podem ser por problemas térmicos, carregamentos indesejados e bem como por ataques químicos. As consequências dessas fissuras podem levar as estruturas a uma redução do tempo de vida útil [4 6]. Essas danificações nas estruturas de concreto podem impactar o seu custo ao longo do tempo, haja vista que serão necessárias intervenções para o tratamento deste dano, fato que possivelmente irá gerar custos de mão de obra para manutenção e prejuízos se a edificação tiver que ser isolada para execução do reparo.

Neste aspecto, técnicas denominadas de autocicatrização de fissuras têm sido pesquisadas como forma de aumento de vida útil das edificações. Entre elas, o uso de bactérias resistentes que depositam carbonatos resultantes de suas atividades metabólicas. Sendo assim, este trabalho irá investigar a aplicabilidade do microrganismo Lysinibacillus sphaericus como forma de agente autocicatrizante para estruturas de base cimentícia. Este trabalho se restringirá ao estudo do microrganismo citado, ou seja, não há experimentação do mesmo em contato com materiais de base cimentícia.

Sendo assim, este trabalho tem como objetivo verificar se o microrganismo $L$. sphaericus apresenta ou não crescimento quando em contato com meio nutriente com $\mathrm{pH}$ neutro $(\mathrm{pH} 7)$ e alcalino ( $\mathrm{pH} \mathrm{9,10,11,} \mathrm{e} \mathrm{12)} \mathrm{através} \mathrm{da} \mathrm{adição} \mathrm{de} \mathrm{hidróxido} \mathrm{de}$ cálcio como agente de modificação do $\mathrm{pH}$ do meio. $\mathrm{E}$ também verificar se o mesmo precipita o composto químico carbonato de cálcio, em meio com $\mathrm{pH}$ neutro, quando adicionado o composto químico Nitrato de Cálcio como agente de enriquecimento de cálcio $\left(\mathrm{Ca}^{2+}\right)$ no meio. Isso, para que possa ser sugerida a sua aplicabilidade como um microrganismo capaz de ser utilizado como agente de autocicatrização em estruturas de base cimentícia.

\section{Materiais e Métodos}

O experimentos foram desenvolvidos de modo a seguir a linha de raciocínio conforme representa o fluxograma da Figura 1. Analisando o mesmo observa-se que foram realizados dois experimenos em paralelo. Primeiro, foi induzido o crescimento do microrganismo em $\mathrm{pH}$ alcalino a fim de verificar se o mesmo apresenta crescimento nesse meio. Segundo, foi efetuada a adição do composto químico Nitrato de Cálcio com o intuito que o meio ficasse rico em cálcio, depois foi feito o experimento de diluição seriada para verificar a concentração do meio de cultura e por fim foi induzida a precipitação do microrganismo L. sphaericus para verificar se o mesmo precipita ou não o mineral carbonato de cálcio. 


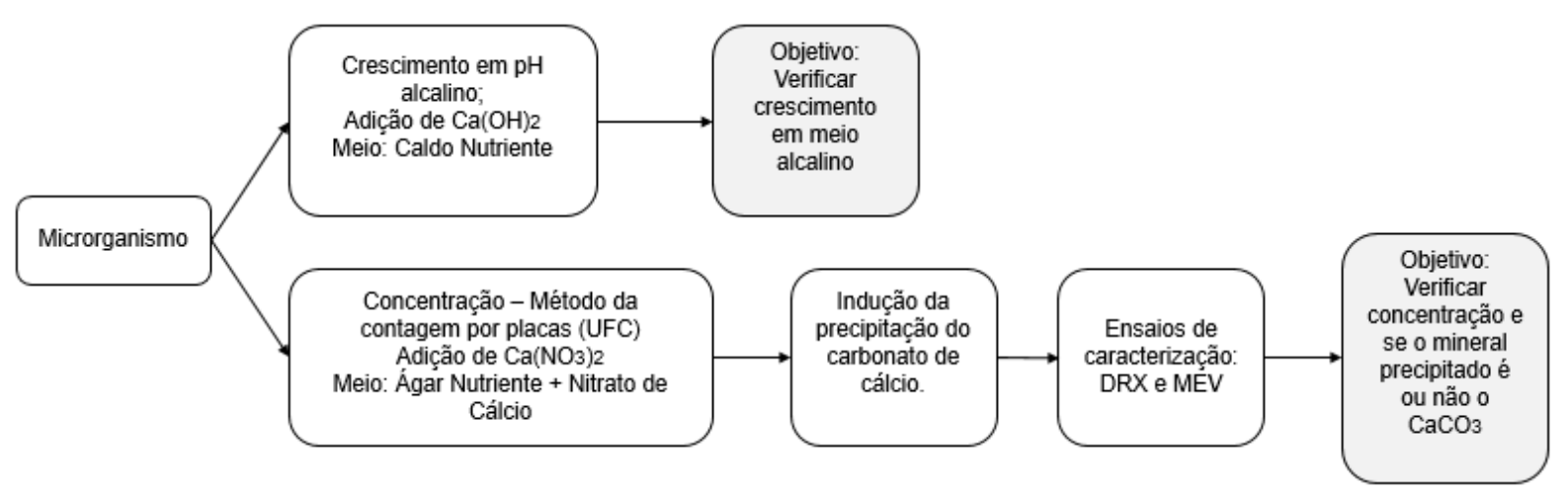

Figura 1: Fluxograma do experimento

As variáveis de resposta deste experimento são o crescimento do microrganismo nos pH's 7, 9, 10, 11 e 12, a concentração do meio de cultura em UFC/ml (UFC - unidade de formação de colônia), e a identificação dos cristais de carbonato de cálcio $\left(\mathrm{CaCO}_{3}\right)$ pelos ensaios de caracterização DRX e MEV. Os parâmetros fixados nesse experimento foram: o meio nutricional base para o crescimento do microrganismo (Ágar/Caldo Nutriente), a temperatura de incubação $\left(30^{\circ} \mathrm{C}\right)$ e adição do reagente rico em cálcio na concentração de $5 \mathrm{~g} / \mathrm{l}$ de água destilada (Nitrato de Cálcio).

\subsection{Materiais}

\subsubsection{Lysinibacillus sphaericus}

O microrganismo utilizado foi o Lysinibacillus sphaericus INCQS-422 (ATCC 14577) no qual o mesmo foi fornecido pela Fundação Oswaldo Cruz (Fiocruz).

\subsubsection{Reagente à base de Cálcio}

O reagente utilizado para potencializar o crescimento do microrganismo e induzir a formação de minerais carbonatos foi o Nitrato de Cálcio $\left(\mathrm{Ca}\left(\mathrm{NO}_{3}\right)_{2}\right)$. O reagente foi fornecido pela Central de Reagentes da PUC-PR. O mesmo foi diluído na proporção de $5 \mathrm{~g}$ para 1 litro de água destilada.

\subsubsection{Nutriente base}

O nutriente base para o crescimento dos microrganismos foi o Ágar/Caldo Nutriente. O nutriente adquirido foi o da marca Kasvi. A composição do nutriente é dada pela proporção de $1,0 \mathrm{~g}$ de extrato de carne, 2,0 $\mathrm{g}$ de extrato de levedura (base proteica rica em carboidratos), 5,0 g de peptona (proteína semi-digerida que serve como fonte de nitrogênio e carbono) e 5,0 g de cloreto de sódio. A diluição adotada foi de $13 \mathrm{~g}$ para 1 litro de água destilada, conforme indicação do fabricante.

\subsection{Métodos}

\subsubsection{Crescimento em $\mathrm{pH}$ alcalino}

Foram realizados os crescimentos dos microrganismos com alteração do $\mathrm{pH}$ do meio de cultura. Além do $\mathrm{pH}$ neutro $(\mathrm{pH} 7)$, quatro $\mathrm{pH}$ 's alcalinos foram adotados: $\mathrm{pH}=9$, $\mathrm{pH}=10, \mathrm{pH}=11$ e $\mathrm{pH}=12$. O objetivo deste experimento é simular o meio de uma estrutura de concreto, que tem característica alcalina. 
OLIVEIRA, I. A.; ANJOS, J. C. S.; MEDEIROS, M. H. F. INVESTIGAÇÃO DO MICRORGANISMO LYSINIBACILLUS SPHAERICUS COMO AGENTE DE AUTOCICATRIZAÇÃO EM MATERIAIS DE BASE CIMENTÍCIA. $4^{\circ}$ Simpósio Paranaense de Patologia das Construções (40 SPPC), artigo 4SPPC146, pp. 411 - 419, 2019. DOI: 10.4322/2526-7248.063

A alteração do $\mathrm{pH}$ do meio de cultura foi realizada pelo composto químico hidróxido de cálcio $\left(\mathrm{Ca}(\mathrm{OH})_{2}\right)$ para manter o meio rico com o elemento cálcio e semelhante à solução do poro do concreto. O controle foi feito com auxílio de um medidor de $\mathrm{pH}$ de bancada e as adições do $\mathrm{Ca}(\mathrm{OH})_{2}$ foram feitas até atingirem as medidas de $\mathrm{pH}$ citadas.

Após a modificação do $\mathrm{pH}$ do meio de cultura o microrganismo foi adicionado aos mesmos para induzir o crescimento. Para isso, o meio de cultura após a inoculação do microrganismo foi submetido a uma estufa a $30^{\circ} \mathrm{C}$ por 24 horas para induzir 0 crescimento. Após esse período o meio líquido foi submetido à leitura por espectrofotometria para avaliar o crescimento em função da concentração do meio.

\subsubsection{Concentração do meio - contagem em placas}

Este método consiste na determinação do tamanho de uma população bacteriana. $O$ método considera que cada formação de colônia na placa de Petri seja oriunda de um único micróbio, então a contagem em placas são frequentemente chamadas de Unidades Formadoras de Colônias (UFC) [7].

No procedimento de contagem, um volume de $1 \mathrm{ml}$ é retirado da amostra a ser quantificada, no qual o mesmo é diluído em meio de solução fisiológica $0,9 \% \mathrm{com}$ volume de $9 \mathrm{ml}$. Assim, cada tubo de ensaio que contém $9 \mathrm{ml}$ de solução fisiológica receberá o volume de $1 \mathrm{ml}$ do tubo anterior. Após as diluições serem finalizadas, os meios são transferidos na quantidade de $0,1 \mathrm{ml}$ para as placas de Ágar Nutriente e Ágar Nutriente + Nitrato de Cálcio $(5 \mathrm{~g} / \mathrm{l})$ que são submetidas a uma estufa a uma temperatura de $30^{\circ} \mathrm{C}$ por 24 horas para iniciar o crescimento. Após o tempo decorrido as placas são contabilizadas pelas colônias que apresentaram crescimento e podem ser notadas a olho nu. A adição do Nitrato de Cálcio tem como objetivo aumentar a concentração de cálcio no meio e também aumentar o nitrogênio que serve como fonte nutricional para os microrganismos. A adição desse produto visa somente 0 estudo do microrganismo em meio líquido e não a sua aplicabilidade em estruturas de concreto.

\subsubsection{Indução da precipitação do mineral carbonato de cálcio}

Para este experimento foram executadas duas amostras, uma sem a adição do Nitrato de Cálcio e a outra com adição. O meio de cultura nutricional utilizado para este procedimeto foi o meio de cultura líquido à base de Caldo Nutriente. Após a execução de $50 \mathrm{ml}$ de meio nutriente os microrganismos foram transferidos para o novo meio e submetidos a uma estufa de agitação a $100 \mathrm{rpm}$ com temperatura controlada a $30^{\circ} \mathrm{C}$ por 14 dias para estimular a precipitação do composto químico carbonato de cálcio. Após esse período foi feita a coleta do meio precipitado para a investigação do composto precipitado.

\subsubsection{Investigação do precipitado por DRX e MEV}

As análises dos minerais por Difratometria de Raios-X (DRX) oriundos da precipitação do microrganismo foi realizada pelo equipamente Shimadzu MAXima XRD-7000, operando a $40 \mathrm{kV}$ e $30 \mathrm{~mA}$. Os parâmetros de ensaio foram: ângulo de $10^{\circ}$ a $70^{\circ}$, passo de $0,017^{\circ}$ e velocidade de varredura de $2 \% \mathrm{~min}$. Para o refinamento dos dados 
OLIVEIRA, I. A.; ANJOS, J. C. S.; MEDEIROS, M. H. F. INVESTIGAÇÃO DO MICRORGANISMO LYSINIBACILLUS SPHAERICUS COMO AGENTE DE AUTOCICATRIZAÇÃO EM MATERIAIS DE BASE CIMENTÍCIA. 40 Simpósio Paranaense de Patologia das Construções (40 SPPC), artigo 4SPPC146, pp. 411 - 419, 2019. DOI: 10.4322/2526-7248.063

foi utilizado o software X'Spert Highscore Plus com banco de dados cristalográficos da International Center for Diffraction Data (ICDD) de 2003.

A Microscopia Eletrônica de Varredura (MEV) foi realizado pelo equipamento TESCAN S8000, que possibilitou visualizar o formato dos minerais precipitados.

Após o processo de indução da precipitação as amostras foram coletadas dos meios de culturas em tubos reagentes tipo Falcon de $15 \mathrm{ml}$ por centrifugação a 1000 rpm por um período de $20 \mathrm{~min}$. Após a coleta do precipitado, o mesmo foi submetido a uma estufa por 48 horas para secagem do composto para ser submetido aos ensaios de caracterização.

\section{Resultados e Discussões}

\subsection{Crescimento do microrganismo a diferentes $p H$ 's}

O microrganismo apresentou maior crescimento quando em $\mathrm{pH}=7$, conforme podese observar na Figura 2. Esse meio de cultura com o pH neutro não foi feito adição de hidróxido de cálcio, haja vista que o mesmo só foi utilizado para efetuar a variação do $\mathrm{pH}$ neutro para com característica alcalino. $\mathrm{O}$ crescimento em $\mathrm{pH}$ neutro foi estatisticamente diferente das demais séries. No qual as séries com $0 \mathrm{pH}=9, \mathrm{pH}=$ $10, \mathrm{pH}=11$ e $\mathrm{pH}=12$ mostraram-se estatisticamente iguais.

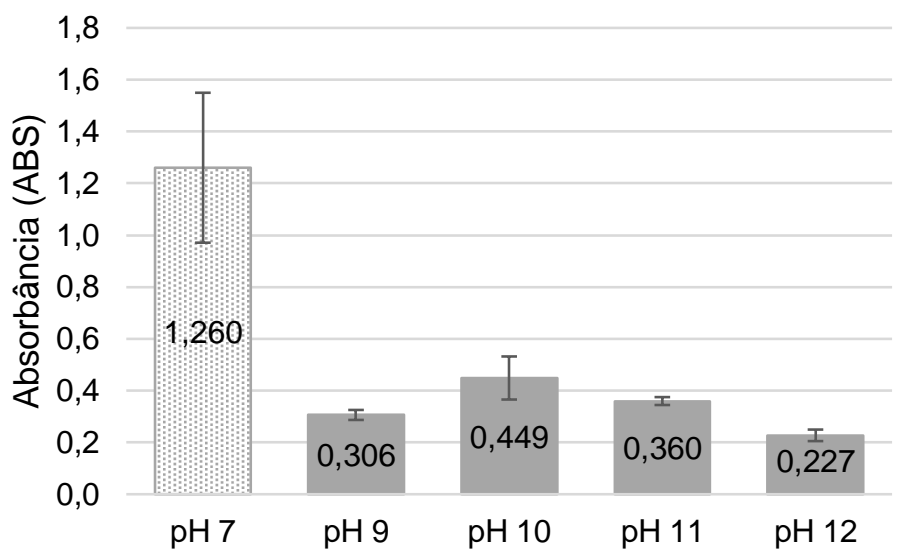

Figura 2: Crescimento do Lysinibacillus sphaericus sob diferentes pH's

De acordo com Stocks-Fischer [8] o pH é um importante fator de calcificação para os microrganismos, pois a precipitação está diretamente relacionada com $0 \mathrm{pH}$ e a concentração molar de $\mathrm{Ca}^{2+}$ em solução. Além disso, ainda no mesmo trabalho, para a precipitação de carbonato de cálcio via microrganismos, quando as mesmas ocorrem em pH 8,3 \pm 1, consolidam cerca de 98\% da concentração inicial do cálcio $\left(\mathrm{Ca}^{2+}\right)$ em carbonato de cálcio. 


\subsection{Contagem por Placas de Petri}

Para as placas com adição de Nitrato de Cálcio a diluição com 1/104 apresentou um número excessivo de UFC, o que impossibilitou a contagem devido ao espalhamento das colônias. As contagens só foram possíveis de serem realizadas a partir da placa de diluição $1 / 10^{5}$, apresentando 766 UFC. A Figura 3 ilustra a contagem feita nas placas, observe que para as placas da esquerda para a direta vão aumentando a diluição variando de $1 / 10^{4}$ até $1 / 10^{7}$ e logo abaixo de cada placa está contabilizada a sua contagem. As diluições ocorreram até $1 / 10^{9}$, mas como não se obteve crescimento nas duas últimas diluições, optou-se por não apresentar a ilustração das mesmas.

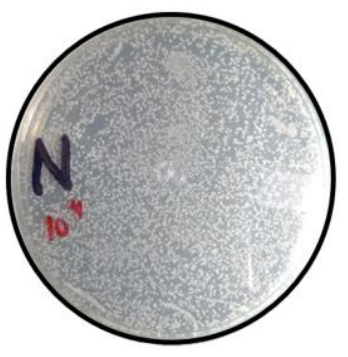

Diluição: $1 / 10^{4}$

Contagem: $n^{\circ}$ excessivo de UFC

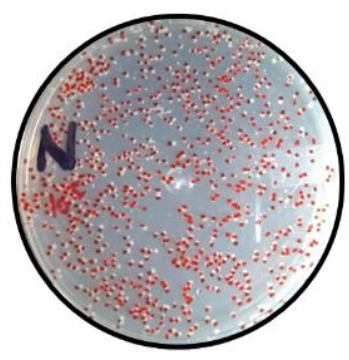

Diluição: $1 / 10^{5}$

Contagem: 766 UFC

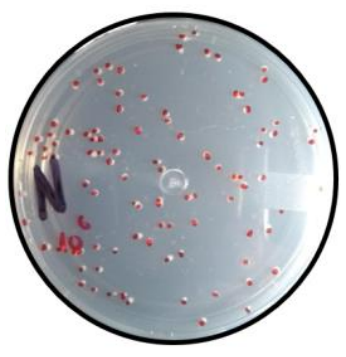

Diluição: $1 / 10^{6}$

Contagem: 96 UFC

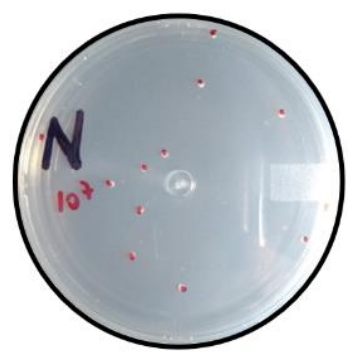

Diluição: $1 / 10^{7}$

Contagem: 12 UFC

Figura 3: Contagem UFC em placas de Petri com meio de cultura Ágar Nutriente + Nitrato de cálcio $(5 \mathrm{~g} / \mathrm{l})$.

A Tabela 1 abaixo apresentam as concentrações de microrganismos após as leituras nas placas de Petri, observe que o microrganismo obtiveram crescimentos próximos. Para o meio sem adição de Nitrato de Cálcio obteve concentração média de 1,22 x $10^{8} \mathrm{UFC} / \mathrm{ml}$ e no meio com adição de Nitrato de Cálcio obteve-se concentração média de $0,97 \times 10^{8}$.

Tabela 1: Contagem e concentração dos microrganismos

\begin{tabular}{ccc}
\hline Diluição & Ágar Nutriente (UFC) & Ágar Nutriente + Nitrato de Cálcio (UFC) \\
\hline $1 / 10^{4}$ & $\mathrm{n}^{\circ}$ excessivo de UFC & $\mathrm{n}^{\circ}$ excessivo de UFC \\
$1 / 10^{5}$ & 958 & 766 \\
$1 / 10^{6}$ & 101 & 96 \\
$1 / 10^{7}$ & 9 & 12 \\
$1 / 10^{8}$ & 2 & 0 \\
$1 / 10^{9}$ & 0 & 0 \\
\hline Média (UFC/ml) & $1,22 \times 10^{8}$ & $0,97 \times \mathbf{1 0}^{8}$ \\
\hline
\end{tabular}

Jonkers e Schlangen [9] trabalham com uma adição da ordem $10^{9}$ células $/ \mathrm{cm}^{3}$ de argamassa. Essa concentração quando dada por volume do corpo de prova (cp) dificulta visualizar qual é a real concentração dos microrganismos quando em meio de cultura, pois não se sabe qual o volume de amostra que foi necessário fazer para se coletar essa quantidade de microrganismos. Contudo, foram dadas as dimensões do corpo de prova (cp) utilizado (cp cilíndrico de $4 \mathrm{~cm}$ de diâmetro e $1 \mathrm{~cm}$ de altura), com isso foi possível calcular o volume, que foi de $12,57 \mathrm{~cm}^{3} / \mathrm{cp}$ e estimar qual a 
quantidade de células por corpo de prova $\left(12,57 \mathrm{~cm}^{3} / \mathrm{cp} \times 10^{9}\right.$ células $/ \mathrm{cm}^{3}=1,257 \times$ $10^{10}$ células/cp). Logo, para o presente trabalho, tem-se a ordem de $10^{8}$ células $/ \mathrm{ml}$ contabilizadas pelo experimento da diluição seriada, então o volume necessário para conseguir a mesma ordem de crescimento de células por cp do trabalho de Jonkers e Schlangen [9] é de aproximadamente $125 \mathrm{ml}$ de amostra de meio líquido. Essas quantidades de microrganismos podem ser coletadas por centrifugação e transferidas para um meio que seja compatível em volume para aplicação no cp adotado.

\subsection{Difratometria de Raios- $X(D R X)$}

Para o meio de cultura sem a adição de Nitrato de Cálcio não houve precipitação de minerais, o que leva a sugerir que para que ocorra a precipitação do composto químico carbonato de cálcio há a necessidade de haver um adiação de algum meio rico em cálcio.

A precipitação ocorreu somente quando o microrganismo $L$. sphaericus foi exposto a um meio de cultura rico em cálcio. O difratograma ilustrado na Figura 4 mostra que o mineral precipitado é a veterita, que uma variação do composto químico carbonato de cálcio $\left(\mathrm{CaCO}_{3}\right)$.

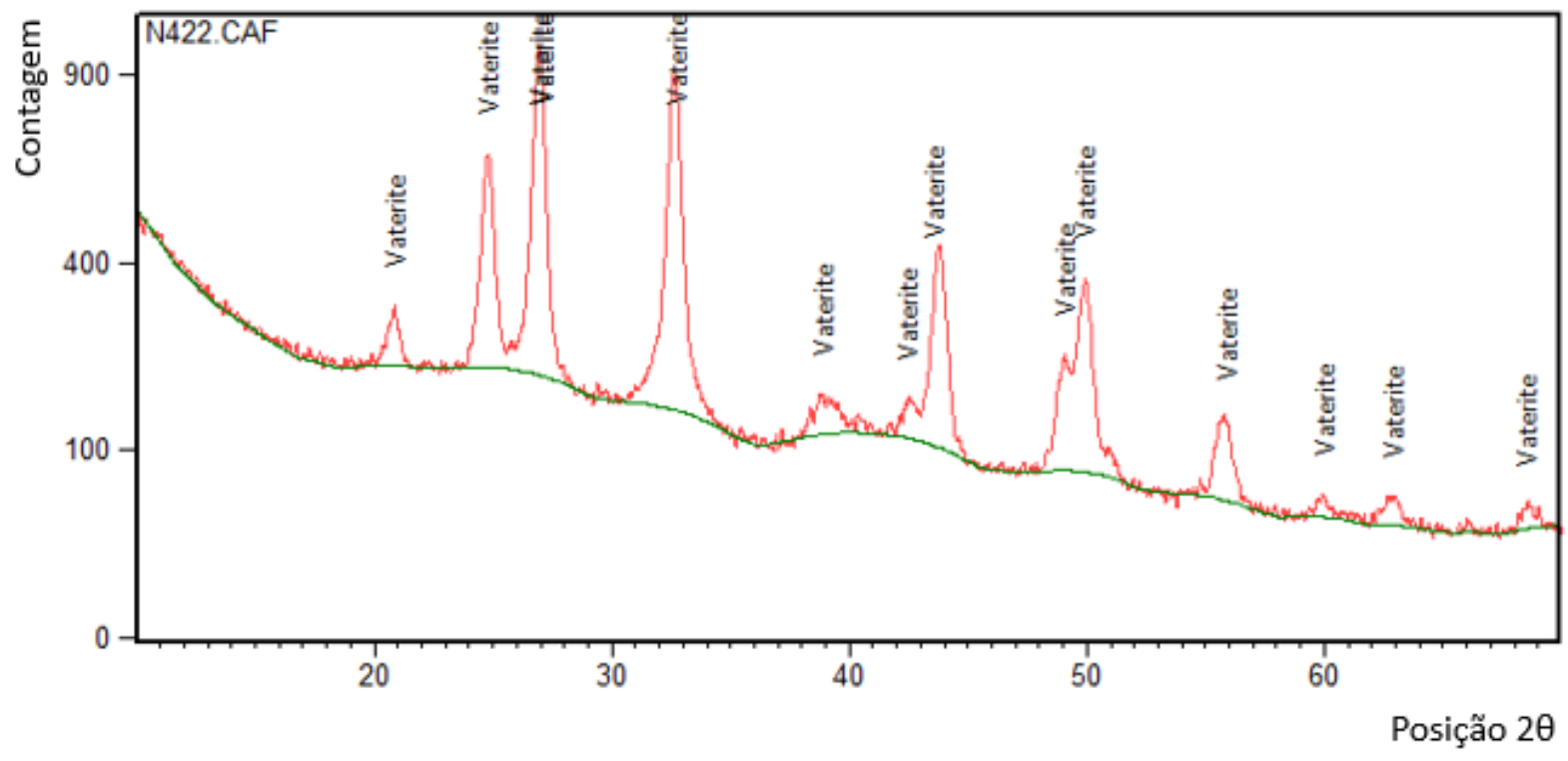

Figura 4: Difratograma do mineral precipitado do Lysinibacillus sphaericus na presença de Nitrato de Cálcio $(\mathrm{pH} 7)$

\subsection{Microscopia Eletrônica de Varredura (MEV)}

$\mathrm{Na}$ Figura 5 são apresentadas as imagens de microscopia para o microrganismo Lysibacillus sphaericus quando exposto ao reagente Nitrato de Cálcio. A imagem à esquerda está com magnificação de 400 vezes e a imagem à direita com magnificação de 8,5 mil vezes, no qual essa foi focada no local indicado por um círculo, como mostra a imagem da esquerda. Pela observação do precipitado sugere que sejam formações de minerais carbonatos de cálcio conforme indicado nas setas. 
O precipitado não foi calcinado, logo pode haver na imagem considerável quantidade de matéria orgânica oriunda dos microrganismos.

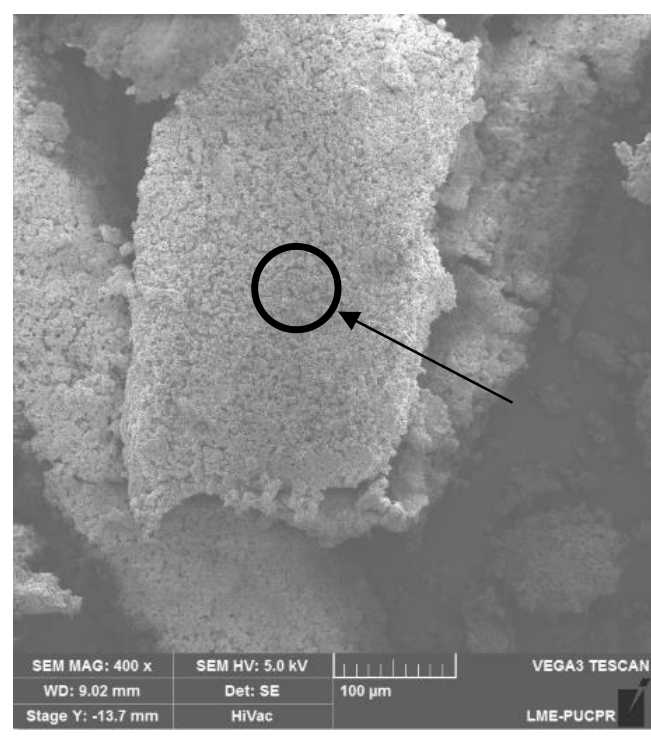

Magnificação de 400x

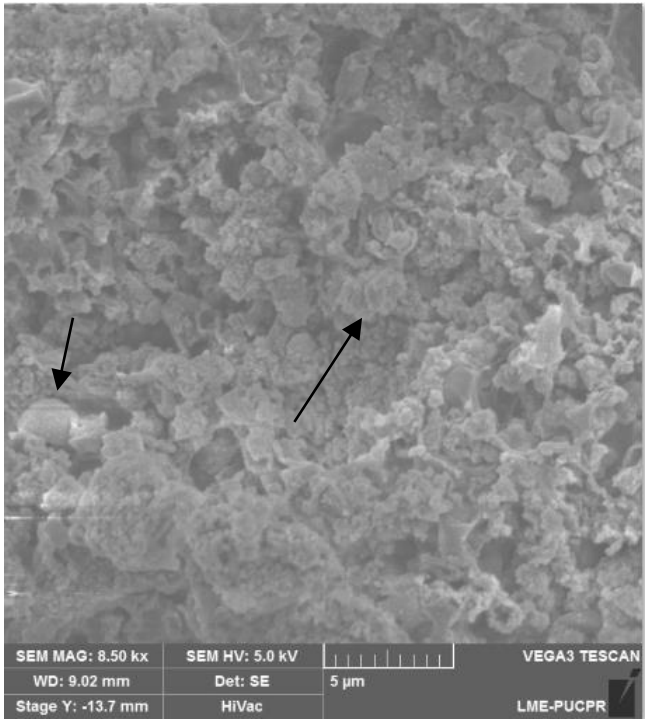

Magnificação de 8,50 kx

Figura 5: MEV do precipitado do microrganismo Lysinibacillus sphaericus quando exposto ao reagente Nitrato de Cálcio

\section{Considerações Finais}

Esse estudo mostrou que há potencial de desenvolvimento, haja vista que o microrganismo de estudo pode precipitar carbonato de cálcio quando exposto a um meio rico em cálcio.

Foi observado o crescimento em $\mathrm{pH}$ alcalino $(\mathrm{pH} 9,10,11$ e 12) do microrganismo, fato que o torna passível de ser utilizado como agente de cicatrização em estruturas de base cimentícia.

Como sugestão para trabalhos futuros fica a indução da precipitação do microrganismo com a adição de reagentes ricos em cálcio em $\mathrm{pH}$ alcalinos, pois são essas faixas de pH's que realmente representam uma situação real de um material de base cimentícia.

\section{Agradecimentos}

Agradecemos à Fundação Oswaldo Cruz pelo fornecimento das cepas para este estudo, ao Programa de Pós-Graduação em Engenharia de Construção Civil da UFPR e a PUC-PR pela parceria nos laboratórios de microbiologia. 


\section{Referências}

[1] M. Seifan, A. K. Samani, and A. Berenjian, "Bioconcrete: next generation of selfhealing concrete," Applied Microbiology and Biotechnology, vol. 100, no. 6, pp. 2591-2602, 2016.

[2] S. K. Ghosh, Ed., Self-Healing Materials: Fundamentals, Design Strategies, and Applications. Weinheim, 2009.

[3] S. van der Zwaag, Ed., Self Healing Materials: An Alternative Approach to 20 Centuries of Materials Science. 2007.

[4] H. M. Jonkers, "Bacteria-Based self-healing concrete," vol. 56, no. April, pp. 1113, 2011.

[5] K. Van Tittelboom, N. De Belie, W. De Muynck, and W. Verstraete, "Use of bacteria to repair cracks in concrete," Cement and Concrete Research, vol. 40, no. 1, pp. 157-166, 2010.

[6] N. Chahal, R. Siddique, and A. Rajor, "Influence of bacteria on the compressive strength, water absorption and rapid chloride permeability of fly ash concrete," Construction and Building Materials, vol. 28, no. 1, pp. 351-356, 2012.

[7] G. J. Tortora, B. R. Funke, and C. L. Case, Microbiologia, 8th ed. Porto Alegre RS: ARTMED EDITORA S.A., 2005.

[8] S. Stocks-Fischer, J. K. Galinat, and S. S. Bang, "Microbiological precipitation of CaCO3," Soil Biology and Biochemistry, vol. 31, no. 11, pp. 1563-1571, 1999.

[9] H. M. Jonkers and E. Schlangen, "Self-healing of cracked concrete: a bacterial approach," 6th International Conference on Fracture Mechanics of Concrete and Concrete Structures, vol. 3, pp. 1821-1826, 2007. 